\title{
Contratempos durante a viagem à Índia, com Gonçalo M. Tavares
}

\section{Kim Amaral Bueno ${ }^{1}$}

\section{Resumo}

Em Uma viagem à Índia, de Gonçalo $\mathrm{M}$. Tavares, a viagem sugerida no título ganha alguns desdobramentos que transcendem à temática diegética da narrativa. $O$ caminho "físico" percorrido pelo protagonista, de Lisboa em direção à Índia, é apenas mote para representar o deslocamento interno de Bloom, atravessando sentimentos que oscilam da culpa ao tédio, da necessidade de fuga à busca pela sabedoria. A recuperação do mito camoniano ocorre pela profanação. Tavares constitui a epopeia de um único homem cujo nome fora emprestado por Joyce (e por toda a tradição literária) na qual não há mais nação, heroísmos nem glórias, apenas a fuga, o permanente trânsito. Operam-se também, na obra, deslocamentos formais da ordem da linguagem e do gênero. O modo como Tavares lê a modernidade se reflete na trama numérica estabelecida entre as centenas de estrofes distribuídas pelos dez cantos da obra. A potência poética profanadora de cada um destes estratos textuais produz um ponto arquimediano poético/linguístico/narrativo capaz de problematizar, no indeterminado espaço da contemporaneidade marcada por um século cuja crença no progresso tecnológico viabilizou as grandes fábricas de morte, o homem que nele deseja conservar a sua "alma", este elemento que, nas palavras de Tavares, ainda "não perdeu a atualidade". A cartografia da viagem poético-narrativa de Bloom por entre o tédio, a fuga e a melancolia é traçada num plano cartesiano de ações, intenções e sentimentos cujo resultado é um Itinerário da melancolia contemporânea, subtítulo desta Viagem à Índia.

Palavras-chave: Gonçalo M. Tavares; viagem; gêneros literários; alteridade.

\footnotetext{
Abstract

${ }^{1}$ Doutoramento em Letras/Literatura Comparada em andamento, na Universidade Federal do Rio Grande do Sul - UFRGS. Professor do Instituto Federal Sul-Rio-Grandense - IFSul.
} 
In Uma viagem à Índia, by Gonçalo M. Tavares, the trip suggested in the title win some developments that transcend thematic narrative. The geographic path traversed by the protagonist, Lisbon towards India, serves to represent the internal displacement of Bloom, through feelings of guilt and boredom, the need to escape the pursuit of wisdom. The recovery of myth Camões is the desecration. Tavares creates the epic of one man whose name had been borrowed by Joyce (and the entire literary tradition) in which there is no nation, heroism or glory, only to escape the constant traffic. Also operate in the text shifts formal order of language and genre. How Tavares reads modernity is reflected in the plot numerical established among the hundreds of stanzas distributed by the ten corners of the text. The poetic force defiling of each of these pieces textual produces an Archimedean point poetic / linguistic / narrative able to discuss, in an indefinite space of the twentieth century, in which the belief in technological progress enabled the large factories of death, the man who wants it retain its "alma", this element that, in the words of Tavares, yet "não perdeu a atualidade". The cartography of the trip poetic-narrative Bloom through boredom, escape and melancholy is plotted on a Cartesian plane actions, intentions and feelings whose result is a Itinerário da melancolia contemporânea, subtitle this Viagem à Índia.

Keywords: Gonçalo M. Tavares; trip; literary genres; otherness.

\section{Introdução}

Este trabalho tem como título "Contratempos durante a viagem à Índia" porque contratempo parece ser o efeito, ou um dos efeitos, produzidos pelo texto no leitor. A palavra "contratempo" pode ser pensada tanto no seu sentido mais imediato, de um "imprevisto", como se o leitor, diante do escrito, se surpreendesse com uma forma "épica" talvez inesperada para a abertura da segunda década do século XXI, como também pode ser entendida enquanto elemento musical, como des-compasso, marca de entre-tempo, que, caso seja possível transpor para a literatura, seria todo entre-lugar, uma vez que o lugar (o espaço) parece ser o elemento reverberante na produção contemporânea, pelo menos portuguesa, a exigir do leitor o trânsito seguro pela espacialização do tempo e da ação.

Assim, pretende-se abordar durante o texto alguns destes imprevistos, destes descompassos com os quais o leitor de Tavares se confronta, principalmente em Uma viagem à Índia, objeto da discussão. A análise segue dividida em duas partes de postulações teóricas acerca de dois "contratempos", de tantos outros possíveis: a questão da viagem enquanto 
temática dentro da tração literária portuguesa; e, a questão do gênero, problemática contemporânea muito viva na produção de Gonçalo m. Tavares.

Para tais sobressaltos no caminho do leitor, ainda não há solução, ou roteiros confiáveis de modo a contorná-los, muito menos a destruí-los por completo. Este texto pretende apenas operar provocações, perscrutar o caminho, atentar para algumas bifurcações, opacidades e armadilhas no complexo "itinerário" traçado por Tavares. Constitui-se como um pequeno esforço de leitura a mover camadas de sentido que, para serem de fato compreendidas e colocadas às claras, exigem mais tempo para verticalizar a leitura, amadurecer os conceitos e digerir os sentidos que emergem do texto e das vidas que o cercam, a ficcional e a real.

\section{Diálogos pelo caminho da literatura}

Gonçalo M. Tavares, jovem escritor nascido em Angola, em 1970, teve sua primeira publicação no ano de 2001 com a obra Livro da Dança. Depois, seguiram-se dezenas de obras, entre romances ensaios, poesia e teatro, dando corpo a um projeto literário ousado, profundamente intertextual e de franca concepção pós-moderna. A série de traduções já existentes, e as em curso, de sua obra, somada aos prêmios já recebidos pelo autor (sobretudo para seu romance Jerusalém) demostra a boa recepção crítica da sua produção no universo lusófono e fora dele.

O seu artifício de escritura, seja em Uma viagem à Índia, seja em suas outras obras, é o diálogo com a tradição clássica e moderna. Em franca associação à postura borgiana, que deliberadamente assume o anacronismo e a imprecisão das atribuições, a ao mosaico de citações, para usar a conhecida expressão de Kristeva, Tavares percorre, antropofagicamente, o cânone ocidental, numa feitura criativa que caracteriza os escritores pós-modernos, em séries infinitas e transtextuais. Aos moldes do próprio Borges, ou de Vila-Matas, por exemplo, o autor estabelece em algumas de suas páginas a cartografia de um bairro ${ }^{2}$ onde convivem Calvino, Brecht e tantos outros colegas de ofício; ou, produz uma "biblioteca portátil" em índice remissivo, na qual encontramos Clarice Lispector ou Joyce. Ou ainda, parodia Homero, Camões e Joyce, estendendo um fio temático pendular, intertextual, e problematizador. Como sugere Maria Tereza Nascimento (2011), Uma viagem à Índia traz no título a confissão sobre

\footnotetext{
${ }^{2}$ A série $O$ Bairro reúne narrativas sobre os seguintes "senhores", que, no universo ficcional, habitam o mesmo bairro: O Senhor Valéry e a lógica, O Senhor Henri e a enciclopédia, O Senhor Brecht e o sucesso, O Senhor Juarroz e o pensamento, O Senhor Kraus e a política, O Senhor Calvino e o passeio, O Senhor Walser e a filosofia, O Senhor Breton e a entrevista, O Senhor Swedenborg e as investigações geométricas.
} 
em qual tradição se insere, ou seja, a da viagem ${ }^{3}$, parodiando a epopeia camoniana. A pesquisadora comenta sobre a vitalidade, ainda hoje, no universo lusófono, de tal temática. Em seu texto, ela vai desvendando as apropriações que Tavares realiza dOs Lusíadas, estabelecendo interessante paralelismo entre as obras, a partir da noção de "empréstimo confessado", de Linda Hutechon (1989).

A partir da obra Biblioteca, Telma Maciel da Silva (2011) realiza um mapeamento das presenças do nome Bloom, o sujeito posto em deslocamento no texto Uma viagem à Índia, em algumas obras de Tavares. Em Biblioteca, "Bloom" aparece como um dos verbetes e nele consta o nome do crítico Harold Bloom. O pequeno texto que constitui o verbete correspondente ao crítico norte-americano traz a expressão "James-Joyce-Bloom". Para a pesquisadora, "Harold Bloom torna-se também Leopold Bloom, o protagonista da epopeia moderna Ulisses" (SILVA, p.4, 2011). No verbete destinado a Joyce, Bloom aparece novamente, o que se repete no trecho destinado a Henrique Vila-Matas. Num movimento que reproduz e problematiza o fazer literário destes dois autores, além de "ironizar" o teórico do cânone ocidental, Tavares cria uma personagem, através de uma "brincadeira", que já nasce clássica. Ainda de acordo com Telma Maciel da Silva, com Bloom,

Tavares promove uma associação entre Camões e Joyce, e, de modo indireto, retoma as epopeias clássicas, uma vez que estas são o "modelo", ainda que de maneira distinta, tanto para Os Lusíadas quanto para Ulisses. Bloom, alter ego de Ulisses - o de Joyce e de Homero - ganha, portanto, mais uma aventura épica, ou melhor, ganha duas aventuras épicas, pois une a profundidade psicológica do Ulisses moderno às peripécias físicas do outro" (SILVA, 2011, p.6).

As operações intertextuais serão as responsáveis pelo deslocamento narrativo operado na superfície do texto, mas também colocarão em movimento os jogos com a tradição e o confronto entre gêneros. A acentuação da força psicológica somada às peripécias físicas no Bloom do século XXI pode ser reveladora de um imenso vazio interno regido pelo tédio, e de um movimento mecânico, inerte, que, ao colocar a personagem "para caminhar", aplica-lhe uma rasteira e o deixa caído no chão. A obra pontua pequenos desabamentos íntimos da personagem durante o trajeto da viagem, permeada de uma sabedoria profética (de quem dispõe de toda a tradição literária e filosófica) lançada pelo narrador. Ela colabora, sem dúvida, para a produção dos contratempos que se seguem.

\footnotetext{
${ }^{3}$ Entende-se literatura de viagem como um conceito operatório que agrega num mesmo território um conjunto de textos documentais ou literários que à viagem (por mar, terra, ar, ou percursos imaginários) vai buscar uma identificação especial. E não só à viagem enquanto deslocamento, percurso mais ou menos longo, mas também ao que, por ocasião da viagem, parece digno de ser registado: a descrição da terra, dos usos e costumes dos seus habitantes, das situações históricas e antropológicas que, por contraste (outra forma de deslocação) com as origens dos viajantes, forma um texto homogéneo e participa da mesma intencionalidade.
} 


\section{Contratempo I: a questão da viagem}

A viagem é tema recorrente nas literaturas de língua portuguesa ${ }^{4}$, não apenas pelo fato de um país geograficamente tão pequenino quanto Portugal ter conquistado um império ultramarino planetário, quanto pela potência que ela confere, a todo viajante, de romper fronteiras e limites culturais, linguísticos, sociais e estabelecer, no confronto com o outro, novas perspectivas sobre seu próprio “eu”. É inevitável estabelecer, pelo menos, dois marcos dentro da produção literária em língua portuguesa cuja temática é a viagem: são eles $O s$ Lusíadas, epopeia do século XVI, e Viagens na minha terra, novela do século XIX. Se Camões, no século XVI, relata os feitos e as conquistas portuguesas durante a viagem para as Índias, comandada por Vasco da Gama, outra é a viagem que, no século XIX, que Almeida Garrett relata em Viagens na minha terra, centrado na utilização da memória, na viagem como temática e motivo da novela, no conceito de nação e no autobiografismo. Ambos os textos, fundamentais para a compreensão de aspectos importantes da lusofonia, foram produzidos em momentos históricos "chave" para a compreensão do ocidente e dos deslocamentos que nos trouxeram ao século XXI.

O século XVI e seus arredores temporais é marcado pelas aventuras ultramarinas dos navegadores da Península Ibérica, que, “desbravando os mares”, levaram ao domínio de seus reinos novas terras de Oriente, África e América. Os cronistas trataram de registrar os percalços, os trajetos, as aventuras, as impressões dos novos povos e das novas paisagens, como se verifica nas "cartas de achamento" enviadas a el rei. Nelas, há não apenas o estranhamento com o nunca visto, diante de um "outro" tão diferente e diante de uma paisagem tão nova, mas, talvez, silenciosamente, o registro de um confronto com a concepção cristalizada de "eu", com a imagem humana representa pelo colonizador, até então única e hegemônica. Os Lusíadas é a narrativa ficcional que estabelece o marco inicial da pátria e da língua portuguesas e aponta para a construção daquilo que podemos chamar de identidade do sujeito português. A viagem, para Camões, é símbolo de vitória, que, dentro do esquema épico camoniano, é avalizada pelas descobertas, pelo trânsito em terrenos desconhecidos e desafiadores, pelas aventuras e pelo heroísmo, elementos que, na lógica textual/social daquela época, comprovariam as virtudes e os méritos desse sujeito/povo e dessa pátria.

\footnotetext{
${ }^{4}$ A referência que faço aqui sobre a viagem no universo ficcional lusófono não ignora o fato de tal temática antecedê-lo e transcendê-lo, pois o deslocamento pertence ao imaginário humano desde a sua constituição, assinalando lugares de origem das narrativas e dos mitos.
} 
Se o século XVI caracteriza a afirmação da pátria portuguesa e produz discursos que se coadunam com o momento de conquista e dominação, o século XIX caracteriza o seu oposto, o declínio, e, invertendo-se a lógica das dominações, a nação passa a curvar-se diante de outro império, o britânico. As revoluções burguesas e a impossibilidade de frear o liberalismo ascendente; a recente "perda" do Brasil, que deixara de ser colônia, a falência do estado, a fuga da família real são questões que, mesmo indiretamente, figuram na "curta" viagem garretteana de Lisboa a Santarém.

Inserido nesta tradição, Gonçalo $\mathrm{M}$. Tavares também se aproveita do motivo da viagem na produção de sua obra, Uma viagem à Índia. A viagem sugerida no título ganha alguns desdobramentos que transcendem à temática diegética da narrativa. $\mathrm{O}$ caminho "físico" percorrido pelo protagonista, de Lisboa em direção à Índia, é apenas mote para representar o deslocamento interno de Bloom, atravessando sentimentos que oscilam da culpa ao tédio, da necessidade de fuga à busca pela sabedoria. Em uma época dominada pela técnica, pela globalização da economia e pelo intercâmbio de informações em tempo real, pelo esgarçamento da imagem, pela convulsão de cartões-postais midiáticos e pela difusão infinita de livros, vídeos, registros de toda ordem sobre o mais recôndito canto da Terra, qual seria o sentido de uma viagem de busca pela sabedoria? Ou, de uma viagem de descobrimentos, sejam eles íntimos ou geográficos/históricos?

A recuperação do mito camoniano ocorre pela profanação. Tavares constitui a epopeia de um único homem cujo nome fora emprestado por Joyce (e por toda a tradição literária) na qual não há mais nação, heroísmos nem glórias, apenas a fuga, o permanente trânsito. A viagem, que se sugere mística, desde o começo é marcada pela descrença. Diferentemente de Vasco da Gama, que parte rumo ao desconhecido, e que através de inúmeras peripécias, obtém o sucesso diante da conquista e através do heroísmo, Bloom, filho de um tempo sem viagens possíveis, no qual a expectativa do desconhecido não acompanha o viajante, encontra ao longo percurso, e no seu final, o tédio e a indiferença. Afinal, todas as cidades são Lisboa, e Lisboa são todas as cidades; todo lugar é a Índia, e a Índia pode ser qualquer lugar. A andança permanente da personagem produz o seu oposto, a imobilidade. A viagem, assim, torna-se estática.

Operam-se também, na obra, deslocamentos formais da ordem da linguagem e do gênero. O modo como Tavares lê a modernidade se reflete na trama numérica estabelecida entre as centenas de estrofes distribuídas pelos dez cantos da obra. A potência poética profanadora de cada um destes estratos textuais produz um entre-lugar, para usar a já célebre 
expressão do professor Silvano Santiago, um ponto arquimediano poético/linguístico/narrativo capaz de dar conta, no indeterminado espaço da contemporaneidade marcada por um século cuja crença no progresso tecnológico viabilizou as grandes fábricas de morte, do homem que nele deseja conservar a sua "alma", este elemento que, nas palavras de Tavares, ainda "não perdeu a atualidade". A cartografia da viagem poético-narrativa de Bloom por entre o tédio, a fuga e a melancolia é traçada num plano cartesiano de ações, intenções e sentimentos cujo resultado é um Itinerário da melancolia contemporânea, subtítulo da Viagem à Índia.

\section{Contratempo II: a questão do gênero}

É desafiador pensar a permanência no modelo épico, dentro de suas postulações tradicionais clássicas, nos dias de hoje. A proposição da obra de Tavares dentro de tal modelo, sob o ponto de visto paródico, explicita a tentativa de "desconstrui-lo no interior do próprio gênero. A profanação textual realizada por Tavares produz um "entre-gênero" cuja estrutura formal é versificada e dividida em estrofes, agrupadas em cantos. Porém, tal forma não obedece a nenhum esquema rígido de organização métrica, sequer apresenta rimas ou qualquer outro recurso lírico de uso deliberadamente repetitivo e estruturado. Sua lógica narrativa interna sugere ser mais a de um romance, de narrador cambiante, que concede espaços sucessivos para a intromissão da voz do protagonista. A onisciência é modelada pela voz (in)consciente do protagonista, produzindo uma bivocalidade narrativa tipicamente prosaica.

Tavares brinca com a forma hibrida do romance, que, para Bakhtin, é um gênero produzido pela fusão dos chamados de gêneros clássicos, a epopeia, a poesia e o drama. Do mesmo modo que ensaia uma forma possível de narrar, o autor revira a poesia para, através dela, ensaiar, talvez, o modo possível de versificar/poetizar as experiências contemporâneas. Em Questões de literatura e de estética, o teórico russo afirma, sobre o gênero romance, que ele seria um "gênero tardio e inacabado", trazendo em sua composição traços capazes de reinterpretar e renovar a linguagem dos gêneros fixos, tornando-os mais "soltos" (BAKHTIN, 1998). Tavares parece tocar neste limiar do "inacabado", em um movimento criativo que radicaliza o conceito bakhtiniano de "dialogismo", caraterística romanesca basilar, estendendo-o à poesia.

Ou seja, produz-se o confronto entre, pelo menos, duas possiblidades de percepção do narrado: 1) na forma de um romance formalmente versificado; ou, 2) na forma de um 
conjunto de poemas ordenados por um fio temático comum, mas que, dado o artifício cartográfico produzido ao fim dos dez cantos, que encerram o corpo em versos do texto, podem ser lidos de modo independente e divididos em temáticas. Pensar a obra de Tavares sob a ótica da epopeia pede que se confronte a clássica visão utópica, incorporada pelo gênero nos seus tradicionais exemplares, à distopia flagrante na obra do escritor português. $\mathrm{O}$ texto encena a sua negação: ao travestir-se de epopeia, Tavares se opõe a Camões, traçando um itinerário "desconstrutor" do gênero e da história, amalgamando o "eu" e o "outro" num único sujeito que descobre que talvez não haja mais o que descobrir, e que entre o épico e o narrativo as distâncias não são incomensuráveis.

Linda Hutcheon, através de Uma teoria da paródia, auxilia a pensar a posição de trânsito deste protagonista Bloom pelos caminhos da história da literatura, e para que se desvende as suas (contra)aprendizagens ao longo dos tempos. Afastando-se da concepção de paródia como um recurso estilístico que deforma o discurso com o qual dialoga, a partir de Bakhtin, Hutcheon (1989) sugere que o homem ocidental contemporâneo tem a necessidade de afirmar o seu lugar na difusa tradição cultural que o cerca, levando-o a buscar deliberadamente a incorporação do velho ao novo em um processo de desconstrução e reconstrução por meio dos recursos estilísticos encontrados na ironia e na inversão. Portanto, a paródia não se caracterizaria apenas pelo seu potencial de subverter e de ridicularizar. $\mathrm{Na}$ pós-modernidade, a paródia tornou-se a própria via predominante da criação artística. A inversão irônica é o seu modus operandi, mas a sua essência está na "auto-reflexividade" (HUTCHEON, 1989, p. 13), na busca do distanciamento crítico e do diálogo independente com a obra de arte, seja na literatura, seja em qualquer outra forma de expressão artística.

A problemática da viagem aparece na obra Uma viagem à Índia sob este ponto de vista auto-reflexivo. A articulação temática e formal com Os lusíadas, como sugerido acima, é inevitável, bem como com toda a tradição da literatura de viagem portuguesa, conforme apontado rapidamente no recorte temático deste projeto. Ou seja, do registro das navegações do século XVI, passando pelo declínio nacional do século XIX representado pelas Viagens na minha terra, até chegar em As naus, por exemplo, romance de Lobo Antunes da década de oitenta do século XX, a viagem de Tavares é um passo adiante no leitura pós-colonial da ação dos ex-impérios/ex-centricos na contemporaneidade. Nesta epopeia de um único homem, cujo início é o ano de 2003, e o término o de 2010, há a primeira década do século XXI posta em questão e em deslocamento, sugerindo a pergunta: quais seriam as possibilidades criativas, 
afetivas e de produção de sentido em um mundo esvaziado pela técnica e pela aparente pasteurização dos sujeitos e suas vidas?

Como Tavares apontou em entrevista, "o grande movimento do século XXI é o da queda". A polissemia do substantivo não descarta, em nenhuma das possibilidades interpretativas, a ideia de movimento vertical, de verticalidade. Seja em referência ao Muro de Berlin, ao World Trade Center ou a um simples sujeito médio em busca de esquecimento de si mesmo: em todos esses lugares percebe-se um declínio anti-heroico, espetacular e vazio.

Maria Alzira Seixo (1998), usando a designação de "herói problemático", proposta por Lukács, questiona esse novo mundo literário a partir das viagens dos descobrimentos em que o homem se apresenta marcado pela realidade empírica, revelando-se uma "identidade perturbada pelas noções de alteridade e de conjunção de diferenças”. Para a ensaísta,

o herói problemático é a personagem ficcional que deixou de sentir a proteção de uma transcendência, e que verifica que o seu percurso mundano pode não ter o acompanhamento tácito de uma divindade que lhe atribui sentido, para descobrir assim o peso da solidão, da imanência das coisas desligadas da sua significação absoluta, tornadas precárias como precária se tornou a sua própria individualidade, presa do problema nodal de existir, de sobreviver, e de resistir à contingência. (SEIXO, 1998, p. 165).

O conflito de Bloom como este homem que se coloca em trânsito para fugir do incontornável problema de existir se coaduna com o problema formal da obra. Há a migração em direção a um "outro": a um outro sujeito; a uma outra possibilidade de perceber a História; a um outro rumo para o homem, que, encarnado em Bloom, representa o homem ocidental contemporâneo médio, mais ou menos o que somos. Além de ir ao encontre de, se não um "novo" fazer literário, de um novo re-fazer, re-escrever, impregnando o texto da certeza irônica de que retornar aos clássicos é o melhor caminho, a melhor rota de fuga, quando se precisa responder, ou escapar, do vazio.

\section{Considerações finais}

A viagem proposta por Tavares é a viagem pela história da literatura. É uma viagem que se apresenta problematizadora do seu protagonista e da sua realidade, muito mais intensamente do que da realidade do outro, da realidade outra, que logo será encontrada. A estaticidade que se percebe no deslocamento de Bloom, a paralisia que, paradoxalmente, comanda o seu movimento, talvez seja indício da necessidade auto-reflexiva desdobrada pela obra, tanto na feitura da personagem ficcional como na estruturação do texto, formalmente 
versificado, porém impregnado de uma dicção prosaico. O retorno para casa se dá só depois da chegada, finalmente, à Índia, paisagem mítica que povoa imaginário ocidental.

Então, vale perguntar qual a importância do enfrentamento/entendimento do "outro" na constituição da identidade da personagem? Quem é este “outro"? Ricardo Timm de Souza, a partir de Levinas, afirma que uma "tensão básica [...] habita cada ser humano individual: a convivência original de um único que nunca está só [...]. Somos únicos, mas definitivamente unidos, definitivamente diferentes" (2000, p.18). É o embate e o encontro que se realiza no contato com o "outro" que pode ser um prolongamento de si. Mas, "Quem é, portanto, o Outro?" (2000, p.62) Souza observa que "é o que não deixa o Mesmo enquanto Mesmo repousar. O Outro é o questionamento de toda a boa consciência [...]” (2000, p.62).

O Outro corrói minhas certezas, me extrai de mim mesmo, delimita o meu desespero e minha solidão aparentemente infinitos e eternos com sua ocorrência, e funda meu persistir na existência - minha subjetividade - para que eu possa, entre muitas outras $\begin{array}{lllll}\text { coisas, } & \text { filosofar } & {[\ldots]} & \text { (SOUZA, } & \text { 2000, }\end{array}$

O "deslizamento" de sentidos entre o "eu" e o "outro" é que dará o rumo de um deslocamento estático, de uma viagem convertida em movimento de queda. Parafraseando Silviano Santiago, é a "dialética rarefeita" entre não se reconhecer "eu” e também não ser "outro" que não apenas paralisa fisicamente o sujeito, mas também o desloca, o derruba, num movimento subjetivo psíquico infinito, tornando-o sempre estrangeiro. Como afirma Júlia Kristeva, em Estrangeiro para nós mesmos, "estranhamente, o estrangeiro habita em nós" (1994, p.10). O confronto com o estrangeiro "começa quando surge a consciência de minha diferença e termina quando nos reconhecemos todos estrangeiros, rebelde aos vínculos e às comunidades" (KRISTEVA, 1994, p.10).

\section{Referências}

BAKHTIN, Mikhail. Questões de Literatura e de Estética: a Teoria do Romance. São Paulo: Unesp/Hucitec, 1998.

. Estética da criação verbal. São Paulo: Martins Fontes, 1997.

CAMÕES, Luís.Os Lusíadas. São Paulo: Ateliê Editorial, 2011.

GARRETT, Almeida. Viagens na minha terra. Porto Alegre, 2012.

HUTCHEON, Linda. Poética do pós-modernismo. Rio de Janeiro: Imago, 1991. 
. Uma teoria da paródia. Lisboa: Edições 70, 1989.

KRISTEVA, Júlia. Introdução à semanálise. São Paulo: Perspectiva, 2005.

$\overline{\text { Rocco, } 1994 .}$

Estrangeiros para nós mesmos. Trad. Maria Carlota C. Gomes. Rio de Janeiro:

NASCIMENTO, Maria Tereza. A melancolia contemporânea da epopeia: Uma viagem à Índia de Gonçalo M. Tavares. Anais do XXIII Congresso Internacional da Associação Brasileira de Professores de Literatura Portuguesa (ABRAPLIP). São Luís, 2011, p.829-839.

SEIXO, Maria Alzira. Poéticas da viagem na literatura. Lisboa: Edições Cosmos, 1998.

SILVA, Telma Maciel da. Gonçalo M. Tavares: brincando de ser clássico. Revista Criação \& Crítica, n6, 2011, p.1-17. Disponível em:

$<$ http://www.fflch.usp.br/dlm/criacaoecritica/dmdocuments/CC_N6_TMSilva.pdf $>$

SOUZA, Ricardo Timm de. Sentido e alteridade: dez ensaios sobre o pensamento de Emmanuel Levinas. Porto Alegre: EDIPUCRS, 2000.

TAVARES, Gonçalo M. Uma Viagem à Índia. Rio de Janeiro: Leya, 2010. 